\title{
UM RELATO DE EXPERIÊNCIA NO ENSINO DE CIÊNCIAS NA MODALIDADE PROEJA EM PERÍODO DE PANDEMIA NO INSTITUTO FEDERAL FARROUPILHA CAMPUS PANAMBI
}

\author{
AN EXPERIENCE IN THE TEACHING OF SCIENCES IN THE PROEJA MODALITY \\ IN A PANDEMIC PERIOD AT THE FEDERAL INSTITUTE FARROUPILHA CAMPUS \\ PANAMBI
}

\section{Carolina Farias da Costa}

Universidade Federal da Fronteira Sul, Campus Cerro Largo, RS, Brasil. E-mail: carolfdacosta@gmail.com

\author{
Alana Rafaela Borsekowsky \\ Instituto Federal Farroupilha, Panambi, RS, Brasil. E-mail: alanaborsekowsky@gmail.com
}

\section{Daniela Carolina Ernst}

Universidade de São Paulo, São Paulo, Brasil. E-mail: daniela.ernst@usp.br

DOI: https://doi.org/10.46550/amormundi.v2i5.117

Recebido em: 12.08.2021

Aceito em: 08.09.2021

\begin{abstract}
Resumo: O PROEJA (Educação de Jovens e Adultos- profissionalizante) é uma política pública que foi instaurada com o objetivo de superar os dados encontrados. O programa tem por objetivo oferecer oportunidades educacionais para adultos e jovens trabalhadores, que ainda não finalizaram o ensino fundamental ou médio, com a oportunidade de realizar um curso técnico, e assim habilitá-los e preparálos para uma profissão. Devido ao surto do vírus da COVID-19 no início do ano de 2020, as instituições de ensino do país foram obrigadas a se adaptarem ao Ensino Remoto Emergencial (ERE) e a buscar maneiras para que o processo de ensino e de aprendizagem ocorresse nessa modalidade, que era, até então, desconhecida. Este texto partilha o relato de experiências de duas graduandas do curso de Licenciatura em Ciências Biológicas do Instituto Federal Panambi que realizaram seus estágios em uma turma de PROEJA da mesma instituição, de maneira remota no segundo semestre de 2020.
\end{abstract}

Palavras-chave: Ensino. Ciências. PROEJA.

Abstract: PROEJA (Youth and Adult Education - vocational training) is a public policy that was established with the objective of overcoming the data found. The program's objective is to provide educational opportunities for adults and young workers, who have not yet finished elementary or high school, with the opportunity to take a technical course, and thus qualify and prepare them for a profession. Due to the outbreak of the COVID-19 virus at the beginning of 2020, the country's educational institutions were forced to adapt to Emergency Remote Education (ERE) and to look for ways for the teaching and learning process to take place in this modality, which was, until then, unknown. This text shares the experience report of two undergraduate students from the Biological Sciences Degree course at the Instituto Federal Panambi who performed their internships in a PROEJA class at the same institution, remotely in the second half of 2020.

Keywords: Teaching. Sciences. PROEJA. 


\section{Introduçáo}

e acordo com sua lei de criação, os Institutos Federais (IFs), são instituições de
educaçáo superior de educaçáo básica e profissional, pluricurricular e multicampi, especializada na oferta de Educação Profissional e Tecnológicas nas diferentes modalidades de Ensino. Uma das suas principais metas, seria a garantia ao acesso e permanência de estudantes, em especial aos histórica e socialmente excluídos, como os que fazem parte do Programa de Integração da Educação Profissional à Educação Básica na Modalidade Educação de Jovens e Adultos (PROEJA ( ERNST el al 2021).

O programa tem por objetivo oferecer oportunidades educacionais para adultos e jovens trabalhadores, que ainda não finalizaram o ensino fundamental ou médio, com a oportunidade de realizar um curso técnico, e assim habilitá-los e prepará-los para uma profissão (MOURA; HENRIQUE, 2012).

Em sua grande maioria, os indivíduos dessa modalidade de ensino, pertencem às classes socioeconomicamente menos favorecidas da sociedade (RODRIGUES, 2010), o que gera uma série de dificuldades importantes a considerar-se, em especial no atual cenário epidêmico, estando entre elas o acesso às tecnologias que esse modo de ensino exige. Destarte, essa camada da população constantemente precisa conciliar as atividades diárias com as atividades colocadas em meio ao ensino remoto (DIAS, 2020).

Devido ao surto do vírus da COVID-19 no início do ano de 2020, o Brasil paralisou as atividades presenciais em escolas da rede pública e privada desde março do referido ano, a fim de reduzir o crescente número de infectados e diminuir os riscos de contaminaçáo em massa. Destarte, a partir de março de 2020, as instituiçóes de ensino do país foram obrigadas a se adaptarem ao Ensino Remoto Emergencial (ERE) e a buscar maneiras para que o processo de ensino e de aprendizagem ocorresse nessa modalidade, que era, até então, desconhecida. Conforme Parecer no 05/2020 do Conselho Nacional de Educação (CNE), a COVID-19 é:

Uma pneumonia de causas desconhecidas detectada em Wuhan, China, foi reportada pela primeira vez pelo escritório da Organização Mundial da Saúde (OMS) em 31 de dezembro de 2019. O surto foi declarado como Emergência de Saúde Pública de Importância Internacional em 30 de janeiro de 2020.

Em decorrência do fato da doença ser altamente contagiosa e perigosa à saúde humana, professores e alunos tiveram que se adaptar e buscar maneiras do ensino remoto funcionar da melhor maneira possível em todos os níveis de ensino. $\mathrm{Na}$ tentativa de evitar a contaminação, a casa de cada educando tornou-se a nova sala de aula e a vida escolar parte integrante da vida domiciliar.

Segundo dados de 2018 do Instituto Brasileiro de Geografia e Estatística (IBGE), sabe-se que uma em cada quatro pessoas no Brasil não tem acesso à internet. Em termos numéricos, isso representa cerca de 46 milhóes de brasileiros que não têm esse acesso. Com as aulas ocorrendo de maneira online, essa modalidade se torna inacessível a muitos educandos no âmbito do território nacional.

Di Pierro (2005) menciona que a maioria das pessoas que buscam o Ensino de Jovens e Adultos (EJA) no período noturno sáo adolescentes e jovens pobres, que estáo em processos escolares descontínuos, marcados por insucessos e desistências. A procura por essa modalidade 
de ensino vem de uma combinação de fatores ligados ao mercado de trabalho, e ocorre por meio da exigência de credenciais escolares para atuaçáo profissional.

Logo, de maneira geral, esses alunos se caracterizam como indivíduos mais carentes ao acesso e domínio das tecnologias, com obrigaçôes maiores do que indivíduos das outras modalidades de ensino, visto que eles precisam conciliar as suas tarefas cotidianas e de trabalho com a rotina de estudos, resultando assim em uma dificuldade maior para os sujeitos que participam desta modalidade, principalmente no que se refere às práticas didático-pedagógicas a serem adotadas para contemplar as suas especificidades (MONTALVÁO NETO et al., 2021).

Nota-se que permeia no espaço do PROEJA uma diversidade de perfis dos educandos, que possuem singularidades e experiências diversas. De maneira geral, todos os educandos dessa modalidade buscam um objetivo em comum: a escolarização/formação em espaços escolares diversos, dentro de uma mesma modalidade de ensino (LIMA et al., 2020). Assim, depreendese que esse público é formado por estudantes que requerem um olhar apurado e atento sobre o modo como desenvolvem e aprendem os conteúdos curriculares (NAKAYAMA, 2007).

Desse modo, destacamos a dificuldade que já havia na EJA e o novo desafio de se trabalhar com esses indivíduos sabendo da carência financeira e intelectual envolvida no sistema educacional abordado nesse momento de ERE, no qual as Tecnologias da Informação e Comunicação (TIC) são ainda mais predominantes. Também é válido mencionar as interfaces ligadas ao trabalho $\mathrm{e}$ os cuidados domésticos atribuídos nesse momento a esses indivíduos, além de responsabilidades com cônjuges e possíveis dependentes, tais como os filhos. Desse modo, Montalvão Neto et al. (2021, p. 367) ressalta que "a forma de ensino não presencial, requer que o trabalho docente seja ressignificado, de maneira a proporcionar um ensino diversificado, com práticas pedagógicas inclusivas".

\section{Desenvolvimento}

Diante do cenário descrito, o presente trabalho tem o objetivo de apresentar a vivência de duas acadêmicas autoras deste manuscrito, em meio às suas experiências de Estágio de Docência, realizado de maneira remota no segundo semestre de 2020.

Este processo formativo ocorreu no espaço-tempo da disciplina de Estágio Curricular Supervisionado IV, vinculada ao Curso de Ciências Biológicas do Instituto Federal Farroupilha (IFFAR), Campus Panambi. A experiência docente aconteceu em uma turma do PROEJA do IFFAR, especificamente em uma turma do curso Técnico em Edificaçóes, contando com 12 educandos entre 20 e 50 anos.

O presente trabalho apresenta-se como um relato de experiência de duas acadêmicas da Licenciatura em Ciências Biológicas em seus Estágios de Docência, realizados de maneira remota no segundo semestre de 2020. Segundo o Instrutivo para Elaboraçáo de Relato de Experiência da UFJF (2017), esse tipo de texto descreve precisamente uma dada experiência que possa contribuir de forma relevante para sua área de atuação. $\mathrm{O}$ material conta com uma descrição perante uma vivência profissional tida como exitosa ou não, mas que contribui com a discussão do assunto, a troca de ideias, para que assim ocorra a melhoria da discussão em torno desse assunto.

Ainda segundo o Instrutivo, o relato de experiência traz as motivaçóes ou metodologias para as açôes tomadas na situação e as considerações e/ou impressões do relator. O relato é feito de 
modo contextualizado, com objetividade e aporte teórico. Vale lembrar que não é uma narração emotiva e subjetiva, nem uma mera divagação pessoal e aleatória. Isso porque, a nosso ver, relatar a experiência vivenciada em sala de aula "não acaba apenas no registro de narrativa, mas procura fazer visíveis e pensáveis questóes educativas que, por meio de narrar, se nos desvendam" (DOMINGO, 2016, p. 15).

Lembrando que nem todas as experiências mostram resultados positivos, mesmo assim, neste estudo consideramos que os relatos são importantes para alertar outros trabalhadores e indicar novos caminhos (Instrutivo para Elaboração de Relato de Experiência - UFJF/ 2017).

As aulas na turma do PROEJA, durante o estágio de docência, foram planejadas considerando o quanto essas açóes interferem no meio ambiente natural e na vida dos demais seres vivos, tais como animais e plantas. As atividades propostas foram pensadas para estimular a conscientização ambiental de todos os envolvidos.

Como Siqueira (2011, p. 18) ressalta, "a presença humana tem deixado rastros de destruição, interferindo em habitats, produzindo resíduos e poluentes, alterando o equilíbrio dos ecossistemas". Assim, consideramos que trazer esses tópicos como uma pauta a ser abordada em sala de aula é uma maneira de ir ao encontro de futuros impactos antropogênicos por meio de uma abordagem que busca a conscientização sobre as questóes socioambientais.

Com base na premissa anunciada, destacamos que as aves são animais que possuem imensa importância para o equilíbrio ecológico, pois são elas que dispersam sementes, controlam populaçóes de insetos, ratos e cobras, auxiliam na decomposição de matéria orgânica e atuam também como polinizadoras (HANZEN; GIMENES, 2012). Por possuírem um importante papel na vida terrestre, Hanzen e Gimenes (2012) ressaltam a importância do conhecimento acerca desses animais e de sua conservação. Os autores também explicam em seus estudos o quanto a educação ambiental, implantada desde a educação básica nas escolas, estimula o cuidado com os demais seres vivos, especialmente com as aves, além de possibilitar o contato dos educandos com a fauna e flora por meio de observaçóes e de estudos.

Como mencionado, a EJA possui muitos problemas devido à falta de investimento nessa modalidade de ensino, por parte das políticas públicas, em seu modo presencial. No ensino remoto crescem ainda mais as dificuldades a serem pensadas e solucionadas a seu respeito. Isso porque, como dissemos, a EJA é formada majoritariamente por jovens e adultos carentes, tanto financeiramente quanto em relação ao acesso e domínio de TIC.

Considerando o cenário exposto sobre a EJA e o ERE, a partir de entrevistas e conversas com a professora da turma, que ocorreram através de conversas pelo GoogleMeet, foi possível traçar um plano de quais TIC poderiam ser usadas com a turma. O principal meio de comunicaçáo utilizado nas atividades foi o aplicativo mais utilizado pelos educandos da turma, o WhatsApp. Usando esse aplicativo como principal canal de envio de mensagens e de diálogo com os educandos, foi necessário pensar em aulas que pudessem ser elaboradas e enviadas a partir dele.

Em um primeiro momento, outras plataformas foram utilizadas, como, por exemplo, o Google Meet, a partir do qual realizou-se alguns encontros com os educandos. Porém, decorridas algumas aulas, os educandos passaram a não mais acessar com frequência o link dos encontros síncronos. Tentou-se, então, o e-mail da turma, que também, posteriormente, não teve retorno positivo. 
A nosso ver, um dos possíveis motivos da plataforma Google Meet não ser tão viável seria, a priori, em função da internet dos educandos ser limitada, visto que esta é uma plataforma que consome dados de internet. Ademais, observamos outros possíveis fatores limitantes, tais como a falta de familiaridade dos estudantes com a plataforma e uma provável falta de tempo desses educandos (em casa) para participar das atividades propostas, mesmo as aulas ocorrendo em horário regular de aulas da turma.

A seguir, relatamos as experiências vivenciadas nesta proposta de ensino. Apontamos como alguns dos principais autores mobilizados para a realização de reflexôes e para referenciar este relato as pesquisas de Chagas (2020), Hanzen e Gimenes (2012), Kishimoto (1992), Montalvão Neto, et.al (2021) e Segura (2001).

\section{Resultados e discussáo}

O tema a ser trabalhado com os educandos durante o Estágio de Docência foi "A Evolução Antropológica Comportamental e os Impactos da Urbanização". Sabe-se que os seres humanos não são os únicos a habitarem o planeta Terra, pois fazemos parte de um grande meio, onde há a existência de outros seres vivos.

A forma que os humanos estão modificando na atualidade o meio em que vivem ocorre através de construções urbanas para suprir confortos e estéticas não necessárias e vem prejudicando muitos animais, como, por exemplo, as aves. Atualmente, a colisão de aves em construções urbanas que apresentam espelhos ou vidros vem acontecendo quase que diariamente, prejudicando esse grupo que contém uma enorme importância para a dispersão de sementes e para a manutenção e equilíbrio do nosso ecossistema (RIBEIRO et al. 2013).

Com o aumento de construçôes, da iluminação artificial, da poluição sonora e da modificação visual, o espaço natural foi modificado permanentemente (WILCOX e MURPHY, 1985, MARZLUFF; EWING, 2001, MCKINNEY, 2002). Essa urbanização atua como um filtro biológico para comunidades naturais, selecionando espécies tolerantes ou intolerantes aos efeitos das mudanças na estrutura e composição do habitat (CROCI; BUTET; CLERGEAU, 2008, MCKINNEY, 2008).

Saber as características básicas dos animais que nos rodeiam pode ser muito interessante, pois cada um, a partir de suas especificidades, possui uma funçáo importante para o equilíbrio ecológico. Como explicam os autores Hanzen e Gimenes (2012, p.1), "as aves, assim como os demais animais, são de grande importância para o meio ambiente, sabe-se que elas auxiliam na polinização de plantas, na dispersão de sementes, no equilíbrio ecológico”. Por isso, o conhecimento acerca desses animais é importante.

De acordo com Segura (2001), a educação ambiental representa um instrumento fundamental para uma possível alteração do modelo de degradação ambiental vigente. Nessa perspectiva, acredita-se que uma educação que leve para dentro da sala de aula assuntos como conservação ambiental, importância dos ecossistemas e biomas, equilíbrio ecológico e preservação de espécies é o que fará a mudança futuramente. É com base nessa concepção que apresentamos a seguir as nossas experiências com a temática durante o estágio.

Com fator físico limitante, organizamos o material que seria disponibilizado aos alunos com base nas aves que são encontradas no município de Panambi, região noroeste do 
estado do Rio Grande do Sul. Essa organização se deve ao fato de que acreditamos que um material que valorize a fauna local poderia aproximar os alunos do tema, visto que eles teriam algum conhecimento prévio sobre a questão, com base em suas vivências cotidianas. Assim, nesse material organizamos as imagens das aves de acordo com a sua fisiologia, o papel que desempenham no ambiente em que estáo inseridas e os impactos que esses animais sofrem com o advento da urbanização (desmatamentos, redução de habitat, iluminação, perda da área de alimentação e nidação).

Para potencializar as discussóes do que foi enunciado acima, propusemos aos alunos a utilização de um jogo Quiz com curiosidades e perguntas de conhecimentos gerais sobre as aves, criado pelas estagiárias no site GoConqr ${ }^{1}$ e utilizado como recurso didático. Tratava-se de um jogo de verdadeiro ou falso, que poderia ser acessado diretamente pelo celular sem precisar de computador.

Essa proposta foi organizada entendendo que os jogos digitais podem ser definidos como ambientes atraentes e interativos que capturam a atenção do jogador ao oferecer desafios que exigem níveis crescentes de destreza e habilidades (Balasubramanian; Wilson, 2006). Lima (2008) alerta que, para a elaboração de um jogo, essa é uma primeira contradição que o educador precisa enfrentar, e que, caso pretenda utilizá-lo como recurso pedagógico, o educador precisa respeitar as características dessa atividade e atender às exigências do contexto educacional dos educandos. Infelizmente, o uso desse recurso não gerou interesse dos alunos, pois nenhum acessou o jogo proposto.

Acreditamos que a falta de interação com o jogo, deu-se porque muitos dos sujeitos, tinham acesso a internet através de celulares, operacionalizando suas interaçóes na internet através de poucos aplicativos e redes sociais, ou seja, mesmo tendo acesso a internet, não haviam estabelecido familiaridade com a ferramenta proposta. Outra situação identificada, foi a de que mesmo tendo celular, os sujeitos náo tinham internet disponível e utilizavam os pacotes das operadoras. Importante destacar esses dois fatos, a COVID alargou ainda mais o abismo socioeconômico entre os estudantes das escolas públicas, em especial a dos sujeitos inseridos nessa modalidade de ensino de jovens e adultos trabalhadores.

No decorrer das aulas, foi possível perceber que a grande maioria dos educandos visualizaram as atividades enviadas via WhatsApp durante o estágio, porém, nenhum deles nos procurava ou mandava alguma dúvida. Enviamos, PDFs, links de sites e vídeos, contudo, no grupo criado náo existiam conversas, nem mesmo entre eles. Neste ínterim, e a partir do acima exposto,fomos percebendo que, devido ao ensino remoto, cada vez mais os educandos estavam deixando de participar das aulas de Ciências e muitos deles não apareciam nas aulas. Fato que pode ser relacionado com a desmotivação com a situaçáo econômica brasileira, ou seja, dúvidas se vale a pena investir tempo nos estudos, se não existe ao menos a curto prazo perspectiva de mudança desse cenário caótico que nos encontramos.

Em uma das aulas que teve a participação de uma única aluna, foi possível perceber que ela estava na videochamada e, também, arrumando algumas coisas da casa, demonstrando preocupação com o filho, que, horas mais tarde, relatou cuidar dele sozinha. Esse ocorrido mostra a jornada tripla que muitas mulheres enfrentam: cuidar da casa e dos filhos, estudar

1 Disponível em: https://www.goconqr.com/quiz/27759192/quest-es-proeja-iff. Acesso em: 14 jun. 2021. 
e trabalhar. Pirrolas (2017) aponta em seu estudo que as mulheres são ainda as que possuem responsabilidades maiores em relação aos cuidados domésticos e aos filhos em nossa sociedade. Os motivos, baseiam-se na formação da sociedade brasileira, extremamente patriarcal e hierárquica, que delega às mulheres um lugar menor, seus estudos menos importantes, relegando a elas todo o fardo do trabalho em casa.

Por fim, a nosso ver, o mais desafiador de dar aulas remotas é, muitas vezes, ministrar aulas sem um interlocutor direto, ou seja, sem ver os indivíduos que estão por trás da tela do computador. Uma das grandes dificuldades do ensino remoto refere-se à ideia de que a interação entre professor e estudante é mínima (MORGADO, 2003). Isso porque em sala de aula, muitas vezes, o docente consegue identificar as dificuldades que o aluno está enfrentando, devido a esse contato mais próximo, mas, nesse tipo de ensino não presencial, isso muitas vezes não ocorre. Neste ínterim, frisamos que a EJA passou e passa por muitos problemas, pois, como aponta Chagas (2020, p. 9):

Com todas as transformaçóes que a EJA passou no decorrer do tempo ainda sofre preconceito e é percebida como uma modalidade inferior da educação. As verbas orçamentárias para essa modalidade não correspondem à necessidade de alunos, professores e escolas no país. Pouco se investiu na formação daqueles que estariam atuando na EJA, por isso a mesma não tem o respaldo social que precisa para garantir princípios básicos para sua continuidade.

Com base nessas reflexôes, apontamos que ainda há muito o que discutir e pensar sobre essa modalidade de ensino, sobre sujeitos docentes e discentes inseridos nessa modalidade de ensino, precisamos ainda discutir sobre políticas públicas que garantam que a educação continue a acontecer efetivamente com equidade de condiçóes a todos. Além de criar linhas de fuga e resistência, contra todo o contexto. Porém, sem o devido incentivo, ou seja, a criação de políticas públicas de acesso a internet, financiamentos especiais para professores e alunos de escolas públicas, a renda básica universal, a situação torna-se cada vez mais difícil.

\section{Consideraçóes finais}

O presente relato teve o objetivo de apresentar a vivência de duas acadêmicas em torno das experiências vivenciadas durante o Estágio de Docência, realizado de maneira remota no segundo semestre de 2020. Como dissemos, este momento formativo ocorreu na disciplina de Estágio Curricular Supervisionado IV, vinculada ao Curso de Ciências Biológicas do Instituto Federal Farroupilha (IFFAR), Campus Panambi.

Com a mudança de moldes de ensino, o que antes era trabalhado presencialmente em uma sala de aula teve que ser repensado e desenvolvido através de uma tela de computador ou celular, disputando atenção com a vida domiciliar e pessoal dos educandos. Dessa forma, com base nessa experiência e em nossas leituras, acreditamos que a pandemia causada pela Covid-19 mostrou que o ensino apresenta muitas dificuldades, tais como a utilização de metodologias que não facilitam a aprendizagem e a desmotivação de educandos, que não questionam quando apresentam dúvidas. Essas são as observaçôes que temos com base na experiência vivenciada na turma foco de nosso relato, voltada à PROEJA e às suas realidades particulares.

Apontamos ainda que no decorrer das aulas várias dificuldades apareceram: educandos que não compareciam às chamadas pelo Google Meet ou que não respondiam quando solicitados 
no grupo da turma no Whatsapp e que não faziam nenhuma das atividades propostas são alguns exemplos.

Apesar dos contratempos enfrentados, concluímos que o período de docência remota nos trouxe diversos ensinamentos, como, por exemplo, a necessidade de fazer um planejamento que almeja contemplar todos os níveis de compreensão encontrados em sala e que seja significativo e instigante para os educandos. Por fim, ressaltamos que possíveis estudos futuros poderiam enriquecer essas discussões em torno da Educação em Ciências no PROEJA durante o período de Ensino Remoto Emergencial.

\section{Referências}

BALASUBRAMANIAN, N.; WILSON, B.G. Games and Simulations. In: Society for Information Technology and Teacher Education International Conference, 2006. Disponível em < HTTP://sITE.AACE.ORG/PUBS/FORESITE/GAMESANDSIMULATIONS I.PDF $>$. Acesso em: $13 / 07 / 2021$.

CHAGAS, Viviane Ramos da Silva. A EJA NO BRASIL: REFLEXÓES SOBRE SEU HISTÓRICO. VII Conedu. Editora Realize. Anais, 2020.

CROCI, S.; BUTET, A.; CLERGEAU, P. Does urbanization filter birds on the basis of their biological traits? The Condor, Norman, v. 110, n. 2, p. 223-240, 2008.

Di PIERRO, M. C. Notas sobre a redefinição da identidade e das políticas públicas de Educação de Jovens e Adultos no Brasil. Educaçáo \& Sociedade. p. 1115-1139, 2005.

DIAS, J. C. M. "A gente nunca acha que é demais aprender": educação de jovens e adultos: motivações de idosos para buscarem formação escolar em Macaé-rj. (Dissertação de Mestrado em Educação). Programa de Pós Graduaçáo em Educaçáo, Universidade Federal Fluminense. Niterói, Brasil, 2020.

DOMINGO, J.C. Relatos de experiência, em busca de um saber pedagógico. Revista Brasileira de Pesquisa (Auto) Biográfica, Salvador, v. 01, n. 01, p. 14-30, 2016.

ERNST, Daniela Carolina et al. O CURRÍCULO INTEGRADO NA MODALIDADE PROEJA NO INSTITUTO FEDERAL FARROUPILHA: Um olhar a partir dos docentes. Revista PINDORAMA, [S.1.], v. 12, n. 1, p. 19, maio de 2021. ISSN 2179-2984. Disponível em: <https://publicacoes.ifba.edu.br/index.php/Pindorama/article/view/907>. Acesso em: 18 ago. 2021.

HANZEN, S.M; GIMENES, M.R. Importância das Aves Aplicadas à Educação Ambiental em Escolas da Rede Pública de Ensino no Município de Ivinhema-MS. In: Anais do Semex, n. 5, 2012. Disponível em: https://anaisonline.uems.br/index.php/semex/article/view/582. Acesso em: 15/12/2020.

IBGE - INSTITUTO BRASILEIRO DE GEOGRAFIA E ESTATÍSTICA. USO DE INTERNET, TELEVISÃO E CELULAR NO BRASIL. Rio de Janeiro. 2018.

INSTRUTIVO PARA ELABORAÇÃO DE RELATO DE EXPERIÊNCIA. Universidade Federal de Juiz de Fora - Campus Governador Valadares. Instituto de Ciências da Vida Departamento de Nutrição. Acesso em: https://www.uff.br/nutricaogv/files/2016/03/ 
Orienta\%c3\%a7\%c3\%b5es-Elabora\%c3\%a7\%c3\%a3o-de-Relato-de-Experi\%c3\%aancia.pdf. Acesso em: 08/02/2021.

KISHIMOTO, T.M. O jogo, a criança e a educação. Tese de livre-docência. São Paulo: Faculdade de Educação da USP, 1992.

LIMA, Francisca Vieira; BALBINO DA COSTA, Aldemar; LOPEZ, Cléber Lopes \& HARACEMIV, Sonia Maria Chaves. EDUCAÇÃO NÃO PRESENCIAL NA EJA DO PARANÁ EM TEMPOS DE PANDEMIA: UMA PROPOSTA POSSÍVEL?. Revista Interacçóes. p. 106-125, 2020.

LIMA, José Milton. O jogo como recurso pedagógico no contexto educacional. Pró-Reitoria de Graduaçáo. Universidade Estadual Paulista. São Paulo, 2008.

MARZLUFF, J.M.; EWING, K. Restoration of fragmented landscapes for the conservation of birds: a general framework and specific recommendations for urbanizing landscapes.

Restoration Ecology, v. 9, n. 3, p. 280-292, 2001.

MCKINNEY, M.L. Effects of urbanization on species richness: A review of plants and animals. Urban Ecosystems, Duluth, v. 11, n. 2, p. 161-176, 2008.

MORGADO, Lina. OS NOVOS DESAFIOS DO TUTOR A DISTÂNCIA: OS NOVOS DESAFIOS DO TUTOR A DISTÂNCIA: O REGRESSO AO PARADIGMA DA SALA DE AULA. Repositório Aberto. Universidade Aberta. p. 77-89, 2003.

MOURA, D. H. \& HENRIQUE, L. S. PROEJA: ENTRE DESAFIOS E POSSIBILIDADES. HOLOS. n. 28. v. 2. p. 114 - 129, 2012.

NAKAYAMA, A. M. Educação inclusiva: princípios e representação. Biblioteca Digital de Teses e Dissertaçóes da USP, 2007.

MONTALVÃO NETO, Alberto Lopo; MIGUEL, Kassiana da Silva; SIMAS FILHO, José Pedro Simas; DELLA JUSTINA, Lourdes Aparecida. A Educação de Jovens e Adultos em um Cenário de Pandemia: Reflexôes Docentes. SAJEBTT, Rio Branco, UFAC. v.8 n.1, 2021.

PARECER nº 05, de 28 de abril de 2020 do Conselho Nacional de Educação. Brasília, Brasil, 2020.

PIRROLAS, Olga Alexandra Chinita. Conciliação da tripla jornada: como os estudantes trabalhadores conciliam a vida profissional - vida pessoal / familiar - escolar. Repositório Comum, 2017.

RIBEIRO, S.E., R.S. Souza, E.L. Moreira, M.C. Pasa, R.A.T.M. Souza.Contribuição das plantas frutíferas do cerrado na dieta das aves e a importância das aves no processo de dispersão de sementes. Biodiversidade, 2013.

RODRIGUES, R. L. Estado e políticas para a educação de jovens e adultos: desafios e perspectivas para um projeto de formação humana. In Coleçáo didática e prática de ensino: Convergências e tensóes no campo da formaçáo e do trabalho docente. p. 49-59, 2010.

SEGURA, D. de S. B. Educação ambiental na escola pública: da curiosidade ingênua à consciência crítica. Annablume, 2001. 
SIQUEIRA, F.K.A. Biodiversidade e a Interferência Humana. Monografia, 2011.

WILCOX, B.A.; MURPHY, D.O. Conservation strategy: the effects of fragmentation on extinction. The American Naturalist, 1985. 